\title{
DRIVEABILITY SIMULATION OF VEHICLE WITH VARIANT TIRE PROPERTIES
}

The aim of the presented article is to show the possibilities of vehicle tire mathematical model creation and present simulations of a typical driving manoeuvre of a vehicle model equipped with variant tire models.

Keywords: Tire, vehicle, simulation.

\section{Introduction}

The modeling of tires is one of the most complex tasks in the mathematical modeling area. The task consists of real physical model creation, which is most commonly mathematically described by the system of differential or algebraic equations. In a simpler case, these equations are linear. That means the possibility to get acceptable results in acceptable time of calculation. In a case, when the equations are nonlinear, the calculation is much more complicated [1].

\section{Tire modeling}

Simplified mathematical description of the tire behavior during operation leads to linear differential equations. This approach is acceptable in the case the tire is not in the centre of attention by the simulation. This can happen by the evaluation of the complex vehicle dynamics by different simulation scenarios. The main task of the calculation is then reduced to gather dynamic properties of vehicle parts or to analyze the level of vibrations or noise inside the vehicle, the level of frame parts loading, etc. [2].

If the calculation is focused on monitoring driving quality of tires, it is necessary to create a detailed model for calculation, including, for example, [3 and 4]:

material properties of rubber and other structural elements of the tire,

the level of inflators,

shape and height of the tread etc.
This kind of calculation creates the need for application of modern computing resources to get acceptable results. An important factor affecting the duration of calculation is the right choice of the virtual mathematical model and also the method for creating the calculation algorithm.

\subsection{Tire models}

It is possible to make principal distribution of wheel and tire dynamic models to [5]:

simple dynamic models:

- with the point contact (Fig. 1a),

- with the cylinder contact (Fig. 1b).

- complex dynamic models:

- with the solid track (Fig. 1c),

- with the radial springs (Fig. 1d),

- with the radial and tangential springs and elastic ring (Fig. 1e).

continuous dynamic models:

- created by the finite element method (Fig. 1f),

- created by the boundary element method,

- created by other methods of continuum analysis.

The most commonly used model for dynamic analysis of vertical or longitude and transversal oscillations of the vehicle with consideration of wheel - road interactions is the model with radial and tangential springs and elastic ring (Fig. 1e). The detailed description of this model is shown in Figs. 2 and 3.

\footnotetext{
* ${ }^{1}$ Michal Lukac, ${ }^{1}$ Frantisek Brumercik, ${ }^{2}$ Leszek Krzywonos

${ }^{1}$ Mechanical Engineering Faculty, University of Zilina, Slovakia

${ }^{2}$ Mechanical Engineering Faculty, Lublin University of technology, Poland

E-mail: brumercikf@fstroj.uniza.sk
} 


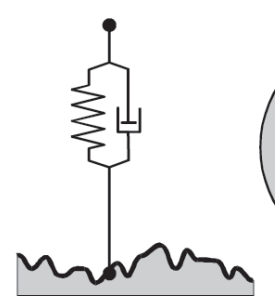

a)

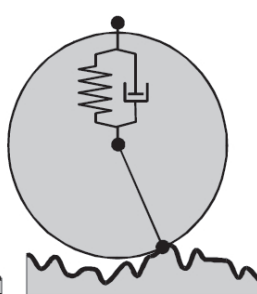

b)

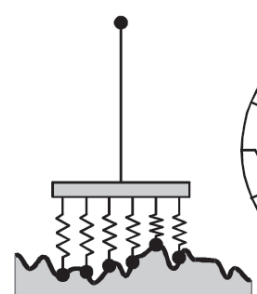

c)

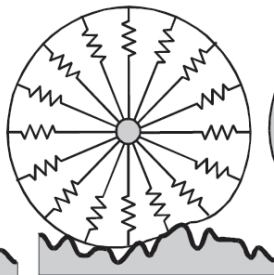

d)

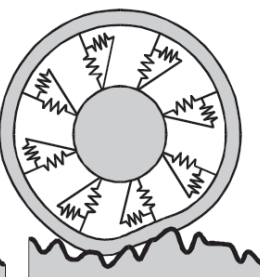

e)

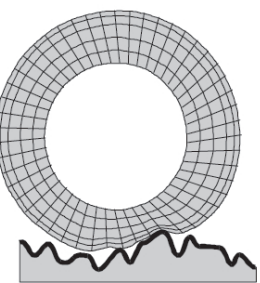

f)

Fig. 1 Tire models (Source: [5])

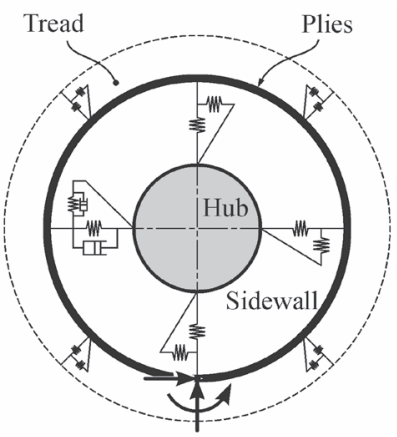

Fig. 2 Detail of tire model inner structure (Source: authors)

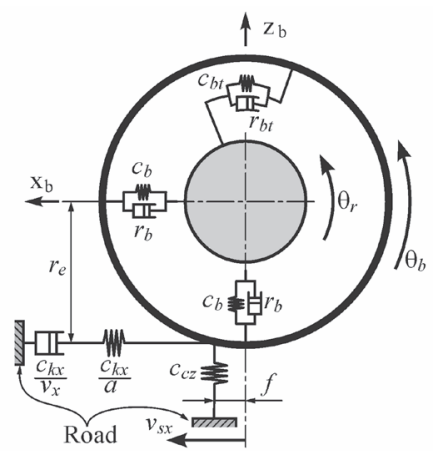

Fig. 3 Detail of tire model with the road interaction (Source: authors)

\subsection{Vehicle models}

One of the models of vehicle dynamics calculation is shown in Fig. 4. This model allows to obtain information about oscillations in the vertical and horizontal direction of the vehicle cab and axle. The tire model is in this case simplified. This model is suitable for prototyping simulation of vehicle stability in the transverse direction as well as the analysis of driving characteristics of the vehicle in the vertical direction [6].

Figure 5 shows a different vehicle model with a more detailed model of dynamic wheel with an elastic disk and also with elastic characteristics of the tire in the vertical direction. This model follows the vertical vibrations and it can be useful after some improvements to solve the dynamics of the wheel - road interaction.

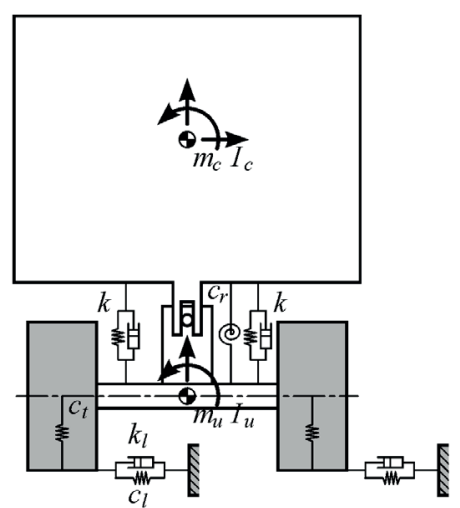

Fig. 4 Vehicle model with a simplified tire model (Source: authors)

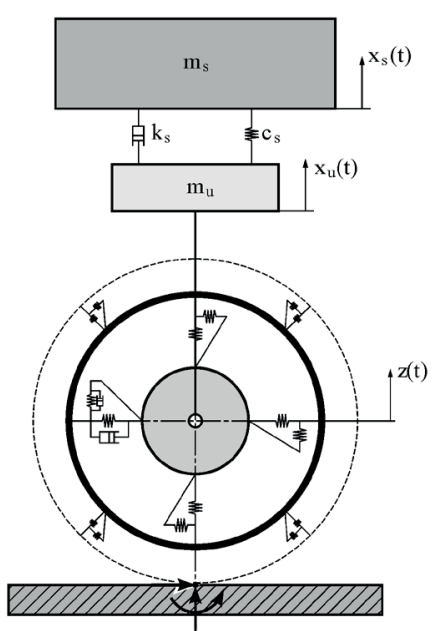

Fig. 5 Vehicle model with the wheel-road interaction

(Source: authors)

The models described above can be used for solving the problems of computer evaluation of the driving characteristics of inflated and underinflated tires and especially the run-flat state. 


\subsection{Calculation software}

The programs, which solve also tasks related to vehicle tires, are based on FEM [7]. The most popular are:

\section{ANSYS, \\ LS-DYNA, \\ ADINA, \\ ABAQUS}

The simulation programs already obtain models of commonly used tires defined by their producers based on the so called "multibody dynamics". The best known software in this class is:

ADAMS with its module Car,

MEDYNA,

NEWEUL,

MATLAB - Simulink.

\section{Simulation of iso lane change manoeuvre}

The task solved in this example was focused on the simulation of a run-flat tire based on the standard driving manoeuvre - the ISO lane change. The model was based on the standard sedan car model platform in ADAMS/Car software (Fig. 6). The conditions and the results of the simulations are described below.

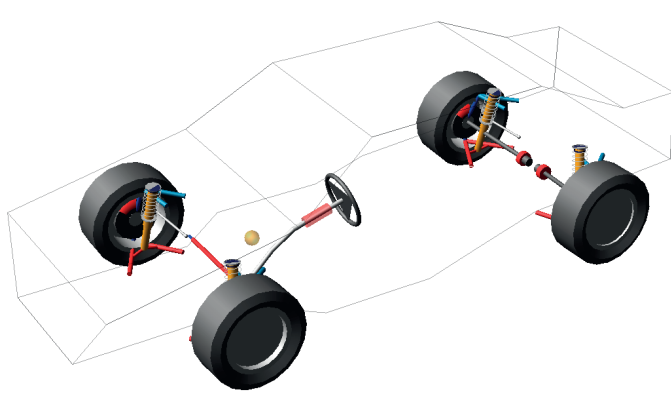

Fig. 6 Standard ADAMS/Car vehicle model (Source: authors)

The simulations were done for 6 types of tires inflated to 220 $\mathrm{kPa}$ and 4 tires under-inflated to $110 \mathrm{kPa}$. The configuration files were developed after experimental measurements of necessary relations.

The car behavior was monitored by the prescribed ISO lane change manoeuvre. This manoeuvre is simulated at an initial velocity of $60 \mathrm{~km} \cdot \mathrm{h}^{-1}$. The acceleration pedal is held in a constant position during the manoeuvre. ADAMS/Driver controls just the direction of the steering axle of the car.

The scheme of the track and vehicle model developed for the overtaking manoeuvre is shown in Fig. 7.

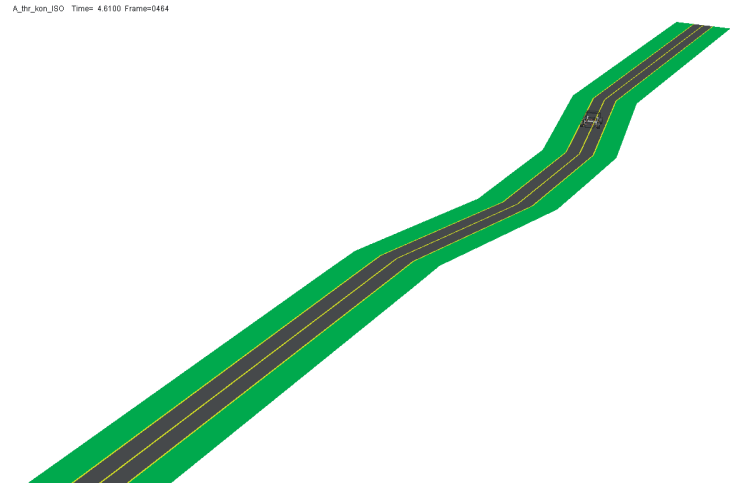

Fig. 7 ISO lane change test track in ADAMS/Car environment (Source: authors)

The goal of the simulation was to follow the car velocity at the end of the manoeuvre. The calculation rating was selected by 0.8 according to the influence of ADAMS/Driver on the progress of the manoeuvre.

Figures 8 and 9 show the velocity diagrams during the manoeuvre for the inflated and under-inflated tires.

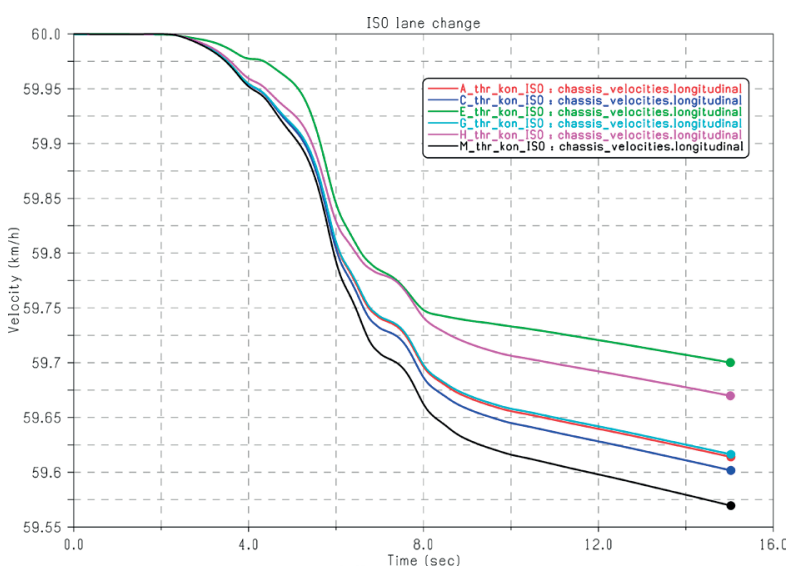

Fig. 8 ISO lane change velocity graph - inflated tires (Source: authors)

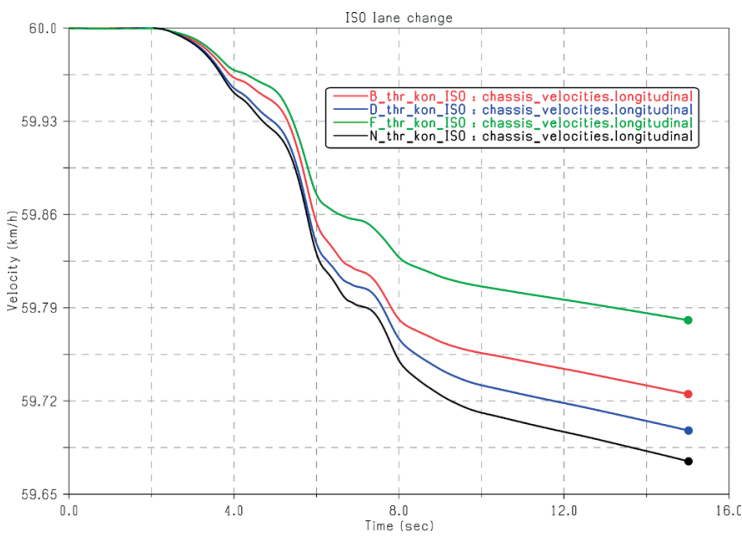

Fig. 9 ISO lane change velocity graph - under-inflated tires (Source: authors) 


\section{Conclusion}

It is possible to create various vehicle models with elastic tires according to the user's specific needs for particular calculations. It depends on the goal of the analysis and the decision which results are significant and which are irrelevant [ 8 and 9]. The presented simulation used the software model of a standard car equipped with tire models defined by the user. There was a specific test done and the velocity results for different tires presented in graphs enable to compare the behavior of the modeled tire types

\section{Acknowledgement}

This paper presents results of work supported by the Slovak Scientific Grant Agency of the Slovak republic under the project No. VEGA 1/0077/15.

This work was supported by the Slovak Research and Development Agency under the contract No. APVV-14-0284.

\section{References}

[1] GLOWACZ, A.: Diagnostics of DC and Induction Motors Based on the Analysis of Acoustic Signals, Measurement Science Review, vol. 14, No. 5, pp. 257-262, ISSN 1335-8871.

[2] BAJOR, I., BABIC, D., PRUSA, P.: Reverse Logistics Simulation Modelling, $16^{\text {th }}$ Intern. Conference on Harbor, Maritime and Multimodal Logistics Modelling and Simulation, HMS 2014, Bordeaux, 2014, pp. 146-153, ISBN 978-88-97999-33-1.

[3] CABAN, J., DROZDZIEL, P., BARTA, D., LISCAK, S.: Vehicle Tire Pressure Monitoring Systems, Diagnostyka, vol. 15, No. 3, 2014, ISSN 1641-6414.

[4] ZEGELAAR, P. W. A.: The Dynamic Response of Tyres to Brake Torque Variations and Road Unevennesses, Delft, 1998.

[5] KAMPF, R., LIZBETIN, J., LIZBETINOVA, L: Requirements of a Transport System User, Communications - Scientific Letters of the University of Zilina, vol. 14, No. 4, 2012, pp. 106-108, ISSN 1335-4205.

[6] TRPISOVSKY, M., PRUSA, P.: Regional Public Transportation Services Modelling, Nase more: J. of Marine Science, vol. 61, No. 3-4, 2014, pp. 77-82, ISSN 0469-6255.

[7] KOMSTA, H., BUKOVA, B., BRUMERCIKOVA, E.: Prospects of Intern. Freight Transport in the East-west Direction. Transport Problems, vol. 11, 2016, ISSN 1896-0596.

[8] DROZDZIEL, P., BRUMERCIKOVA, E., BUKOVA, B.: The Use of Progressive Methods of Serving Passengers, Transport problems, vol. 10, No. 4, 2015, ISSN 1896-0596.

[9] LIZBETIN, J., CERNA, L., LOCH, M.: Model Evaluation of Suppliers in Terms of Real Company for Selected Criteria, Nase more: J. of Marine Science, vol. 62, 2015, pp. 147-152, ISSN 0469-6255. 